\title{
Internalismo e justificação epistêmica não inferencial
}

\author{
Internalism and Epistemic Noninferential Justification
}

*Kátia Etcheverry

\begin{abstract}
Resumo: Este artigo tem como foco a dura tarefa epistemológica que cabe ao fundacionalismo internalista, no que diz respeito às condições internalistas para a justificação (sobretudo a exigência de acesso cognitivo aos fatores que contribuem para a justificação da crença), quando os seus defensores tentam explicar de que maneira crenças básicas podem ser não inferencialmente justificadas com base na experiência. Michael Huemer recentemente ofereceu uma teoria, o Conservadorismo Fenomênico (CF), que ele alega ser a teoria da justificação fundacional mais bem sucedida entre as teorias da justificação internalista. A partir da comparação e do contraste entre a posição assumida por Huemer e as teorias da justificação não inferencial que oferecem uma explicação cuja noção central é a relação de contato cognitivo direto (acquaintance), tentarei expor as fragilidades de $(\mathrm{CF})$, bem como sugerir que a sua única saída seria aceitar que a base epistêmica última de crenças empíricas está na relação de contato cognitivo direto, porque por detrás das "aparências" (seemings) há um contato cognitivo direto. Mas, ao assim fazer, (CF) não mais se distinguiria de teorias do contato cognitivo direto.
\end{abstract}

Palavras-chave: fundacionalismo internalista, justificação não inferencial, contato cognitivo direto, conservadorismo fenomênico, aparências.

\begin{abstract}
In this paper our focus will be on the hard epistemological task internalist versions of foundationalism have, considering the internalist conditions for justification (particularly the requirement of cognitive access to the factors that contribute to doxastic justification), when they try to explain how basic beliefs can be noninferentially justified based on experiences. Recently Michael Huemer has proposed an account of foundational justification, the Phenomenal Conservatism
\end{abstract}

\footnotetext{
* Doutora em Filosofia pela Pontifícia Universidade Católica do Rio Grande do Sul. Professora de Filosofia em estágio pós-doutoral (PNPD-CAPES), junto ao Programa de Pós-Graduação em Filosofia da PUCRS. <katia.etcheverry@acad.pucrs.br>.
} 
(PC), which he claims is the most successful among the internalist theories of justification. By comparing and contrasting his position with acquaintance theories of noninferential justification, we will try to expose (PC)'s fragilities and suggest that its only way out would be to assume that ultimately the beliefs' basis is an acquaintance relation, because behind the seemings there is an acquaintance. But doing so $(\mathrm{PC})$ is no longer different from an acquaintance theory.

Keywords: Internalist Foundationalism. Noninferential Justification. Acquaintance. Phenomenal Conservatism. Seemings.

$\mathrm{O}$

presente artigo tem como ponto central a relação epistêmica que confere justificação a crenças fundacionais atendendo os critérios assumidos por teorias internalistas. Primeiramente, exporei as condições internalistas para a justificação epistêmica e mostrarei o que considero ser um dos maiores problemas a elas colocado na literatura recente. A seguir, passo ao exame das alternativas de resposta disponíveis aos internalistas, contrapondo duas versões de internalismo - uma forte, presente em teorias como a de BonJour e Fumerton; e outra fraca, defendida pela posição conhecida como Conservadorismo Fenomênico, proposta entre outros por Huemer -, concluindo em favor da posição forte.

\section{Justificação epistêmica fundacional: a perspectiva internalista e (alguns) problemas}

Primeiramente, algumas considerações sobre a concepção internalista de justificação. É incontroverso que a noção de justificação epistêmica constitui uma das grandes questões filosóficas, presente já nas reflexões platônicas sobre o conhecimento. A pergunta sobre a natureza dessa propriedade epistêmica tem recebido diferentes respostas, confirmando a tese de Alston ${ }^{1}$ sobre a existência de vários desiderata epistêmicos, aos quais corresponderiam diferentes concepções de justificação. $\mathrm{Na}$ concepção assumida neste artigo, a justificação da crença de um sujeito $S$ em uma dada proposição $p$ é constituída por fatores que indicam, com força variável, mas em grau adequado, a verdade de $p$. Para que a crença de que $p$ seja justificada para $S$, os indicadores da verdade de $p$ devem ser reconhecidos por ele enquanto tais, de modo que a sua relevância na relação epistêmica em questão caracteriza-os enquanto

1 Cf. ALSTON, William, Epistemic Desiderata, in: Philosophy and Phenomenological Research, 53:3 (1993), p. 527-551. 
justificadores da crença. No caso de crenças básicas, conforme a tese fundacionalista, a justificação é obtida por meio de relações que permitem obter apoio epistêmico de estados experienciais do sujeito, dispensando argumentos inferenciais e interrompendo o regresso da justificação por sua independência epistêmica ${ }^{2}$. O ponto de maior sutileza teórica está na explicação de como a crença básica pode se relacionar epistemicamente com a experiência mediante uma relação imediata que lhe proporciona qualificação epistêmica de caráter não inferencial ${ }^{3}$.

Talvez o obstáculo teórico mais importante enfrentado pelo internalismo em sua versão fundacionalista seja aquele apontado por Sellars ${ }^{4}$ a cadeia de justificação não pode encontrar o seu término em experiências sensoriais, porque esses estados não podem ter nenhuma relevância epistêmica, apenas outras crenças do sujeito (estados proposicionais) podem ser justificadores legítimos ${ }^{5}$. É contra essa conclusão flagrantemente contraintuitiva que fundacionalistas levantam a sua bandeira. Uma de suas estratégias mais populares tem sido a de alegar que estados não doxásticos do sujeito, tais como experiências conscientes, podem em determinadas condições se relacionar epistemicamente a conteúdos de caráter proposicional, conferindo-lhes a sua base epistêmica ${ }^{6}$. Assim, o regresso epistêmico

2 Embora o meu interesse neste artigo esteja primordialmente dirigido para a justificação fundacional, é interessante referir que uma crença não básica se distingue de uma básica precisamente por sua característica de ser dependente epistemicamente de outras crenças da estrutura, que lhe conferem suporte mediante uma cadeia suporte justificacional que se estende até as crenças fundacionais.

3 Na literatura, não há consenso, ou mesmo clareza, quanto às condições e características de uma relação não inferencial. Aqueles que aceitam a ocorrência desse tipo de relação a concebem simplesmente como sendo a negação da relação inferencial, ou seja, simplesmente como não assumindo a forma de um argumento no qual a conclusão se segue de premissas. Para o que interessa no momento, não é preciso oferecer uma explicação de relação não inferencial, questão que ainda é objeto de amplo debate entre os teóricos, mas será suficiente aceitar a plausibilidade de uma relação epistêmica, diferente daquela inferencial, caracterizada pela imediaticidade entre os seus relata.

Cf. SELLARS, Wilfrid, Science, Perception and Reality, Atascadero: Ridgeview, 1991.

5 Em poucas palavras, a objeção de Sellars se dirige ao internalista que assume a estrutura fundacionalista de justificação. $\mathrm{O}$ seu argumento procura mostrar que o fundacionalismo é vítima de um dilema fatal: crenças podem ser ou básicas ou justificadas, mas não ambos, porque estados não proposicionais, como é o caso de experiências, não poderiam conferir justificação.

6 Cf. entre outros BONJOUR, L. A., Toward a Defense of Empirical Foundationalism, in: DEPAUL, M. (ed.), Resurrecting Old-Fashioned Foundationalism, Oxford: Rowman \& Littlefield Publishers, 2001, p. 21-38; IDEM, A Version of Internalist Foundationalism, in: BONJOUR, L., and SOSA, E. (eds.), Epistemic Justification: Internalism vs. Externalism, Foundations vs. Virtues, Malden: Blackwell Publishers, 2003, p. 3-96; FUMERTON, Richard, Metaepistemology and Skepticism, Lanham: Rowman \& Littlefield Publishers, 1995; IDEM, Classical Foundationalism, in: DEPAUL, M. (ed.), Resurrecting Old-Fashioned Foundationalism, Oxford: Rowman \& Littlefield Publishers, 2001, p. 3-20; HASAN, Ali, Classical Foundationalism and Bergmann's Dilemma for Internalism, in: Journal of Philosophical Research, 36 (2011), p. 391-410; IDEM, Phenomenal Conservatism, Classical Foundationalism, and Internalist Justification, in: Philosophical Studies, 162:2 (2013), p. 119-141. 
pode encontrar a sua parada em crenças que são básicas e justificadas de modo não arbitrário, contra o argumento cético de Agripa $^{7}$, porque essas crenças são justificadas de modo independente da justificação de outras crenças mediante uma relação epistêmica que é imediata, isto é, não inferencial.

As condições para a justificação fundacional têm sido oferecidas a partir de duas perspectivas que se contrapõem: internalista, mais tradicional, e externalista, mais recente. Usualmente, o externalismo é simplesmente apresentado como sendo a negação do internalismo ${ }^{8}$. Colocando grosso modo, enquanto internalistas admitem como justificadores de uma crença apenas fatores que são internos à vida mental do sujeito da crença, os defensores do externalismo entendem que fatores externos podem ser relevantes para a qualificação epistêmica de crenças. A motivação para teorias externalistas está em estabelecer estreita conexão entre justificação e verdade ao colocar condições que são concebidas em função de aspectos objetivos ${ }^{9}$. Para entendermos a intuição central do externalismo, tomemos como exemplo a teoria confiabilista da justificação ${ }^{10}$, segundo a qual crenças justificadas são aquelas formadas por processos cognitivos confiáveis, sendo que a confiabilidade do processo é determinada objetivamente, em função de sua taxa de sucesso em produzir crenças verdadeiras. Nessa perspectiva, a qualificação epistêmica da crença depende de fatores que são externos ao sujeito e, portanto, estão fora de seu alcance cognitivo. Crenças

7 O argumento cético de Agripa pretende mostrar que não há como configurar uma cadeia regressiva de razões com sucesso, uma vez que apenas três alternativas se apresentam: ou (i) a cadeia é linear e encontra um ponto terminal, de modo arbitrário, em uma suposição; ou (ii) a cadeia é circular retornando a certa altura à crença inicial; ou (iii) a cadeia é linear e infinita. Em nenhuma das três situações, alega o cético, temos uma estrutura adequada para a justificação de crenças. Contudo, em resposta ao trilema temos os fundacionalistas que negam o fracasso de (i); os coerentistas negam o fracasso de (ii); e os infinitistas negam o fracasso de (iii).

8 Meu objetivo ao contrastar as concepções internalistas e externalistas de justificação epistêmica é o de ressaltar suas características distintivas, tornando clara a linha demarcatória que estabelece a divisão entre elas, e com isso alcançar uma caracterização apropriada da concepção de justificação internalista.

9 Assegurar a conexão com a verdade é a motivação central dessas teorias, nas quais a justificação da crença (ou a "autorização" (warrant) na terminologia de Plantinga) depende da "confiabilidade do processo cognitivo responsável pela formação da crença" (cf. GOLDMAN, Alvin, What is Justified Belief?, in: PAPPAS, G. (ed.), Justification and Knowledge, Dordrecht: D. Reidel, 1979, p. 1-23; IDEM, Epistemology and Cognition, Cambridge: Harvard University Press, 1986), ou do "sucesso da crença em rastrear a verdade" (NOZICK, Robert, Philosophical Explanations, Cambridge, MA: Belknap Press, 1981), ou de a crença "ser o resultado do funcionamento apropriado" (PLANTINGA, Alvin, Warrant: The Current Debate, Oxford: Oxford University Press, 1993), isto é, de que ao produzir a crença o aparato cognitivo do sujeito esteja funcionando conforme foi designado para funcionar.

10 Cf. GOLDMAN, Alvin, What is Justified Belief?, in: PAPPAS, G. (ed.), op. cit., p. 1-23; IDEM, Epistemology and Cognition, 1986. 
básicas resultam de processos confiáveis, que admitem como dados de entrada estados não doxásticos do sujeito ${ }^{11}$. Por outro lado, o internalismo tem como motivação central a intuição de que uma crença só é justificada quando o sujeito dispõe de razões em favor da verdade da proposição que é crida ${ }^{12}$. A exigência de posse de razões, característica essencial de teorias internalistas ${ }^{13}$, é o que configura o ponto central de ataque tanto da crítica de Sellars, mencionada anteriormente, quanto da recente objeção colocada por Bergmann ${ }^{14}$, que será exposta com maior detalhe a seguir. A condição para a justificação epistêmica, conforme o internalismo de acesso ${ }^{15}$, é a de que os fatores que contribuem para a justificação epistêmica de determinada crença sejam acessíveis cognitivamente ao sujeito da crença. Essa condição dá origem a críticas que requerem do internalista algumas tarefas: (i) especificar quais itens podem ser fatores de justificação, satisfazendo a condição de acessibilidade cognitiva em

11 Embora a questão enfocada presentemente seja a explicação para a justificação não inferencial de crenças básicas, é interessante mencionar que, conforme o confiabilismo, a justificação das crenças não básicas é obtida quando o processo cognitivo relevante tem como dados de entrada apenas outros estados de crença justificada, sendo que a confiabilidade do processo propiciará a transmissão da justificação do dado de entrada (input) para a crença resultante (output).

12 A literatura internalista é ampla e variada. Alguns exemplos importantes são: BONJOUR, L. A., A Version of Internalist Foundationalism, in: BONJOUR, L., and SOSA, E. (eds.), op. cit., p. 3-96; IDEM, Replies, in: Philosophical Studies, 131 (2006), p. 743-759; FELDMAN, R. e CONEE, E., Internalism Defended, in: SOSA, E.; KIM, J.; FANTL, J.; MCGRATH, M. (eds.), Epistemology: An Anthology, Malden: Blackwell Publishing, 2009, p. 407-421; FUMERTON, Richard, Metaepistemology and Skepticism, 1995; HASAN, Ali, Classical Foundationalism and Bergmann's Dilemma for Internalism, op. cit., p. 391-410; IDEM, Phenomenal Conservatism, Classical Foundationalism, and Internalist Justification, op. cit., p. 119-141.

13 Há outras maneiras de se caracterizar o internalismo; contudo, para o momento assumirei essa caracterização como correta, pois, apesar de não ser unânime, o internalismo de acesso é bastante popular e me parece capturar a essência da concepção internalista de justificação. A sequência desse texto deve deixar claro por que penso assim. Apenas à guisa de informação rápida sobre a divisão entre internalistas quanto ao que propriamente constitui um justificador, podemos contrapor o internalismo de acesso, que estamos considerando no momento, ao internalismo defendido por Conee e Feldman, por eles denominado de mentalismo, segundo o qual a justificação epistêmica das crenças de um sujeito depende exclusivamente de fatores relevantes para a verdade da crença que são internos à mente do sujeito, sem que haja a exigência de que ele acesse esses fatores. A ideia essencial nessa concepção é a de que, quando o conteúdo mental de duas pessoas é idêntico, a sua justificação relativamente a uma dada proposição será igualmente idêntica, mesmo que uma delas habite um mundo demoníaco e epistemicamente inóspito, no qual as suas crenças são sistematicamente falsas. Cf. FELDMAN, R. e CONEE, E., Internalism Defended, in: SOSA, E.; KIM, J.; FANTL, J.; MCGRATH, M. (eds.), op. cit., p. 407-421. Finalmente, cabe acrescentar que Bergmann em sua crítica não inclui o mentalismo sob o rótulo de internalismo.

14 Cf. BERGMANN, Michael, BonJour's Dilemma, in: Philosophical Studies, 131 (2006), p. 679693; IDEM, Justification Without Awareness: A Defense of Epistemic Externalism, Oxford: Clarendon Press, 2006; SELLARS, Wilfrid, op. cit., 1991.

15 Cf. BONJOUR, L. A., Version of Internalist Foundationalism, in: BONJOUR, L., and SOSA, E. (eds.), op. cit., p. 3-96; FELDMAN, R. e CONEE, E., Internalism Defended, in: SOSA, E.; KIM, J.; FANTL, J.; MCGRATH, M. (eds.), op. cit., p. 407-421. 
seu papel justificador; (ii) identificar as condições nas quais esse acesso pode ser epistemicamente adequado, isto é, quando ele é relevante para a justificação da crença; e finalmente, (iii) estabelecer em que condições o acesso não é gerador de regresso.

A objeção colocada por Bergmann nos permitirá apreciar o peso do encargo internalista. Em sua concepção, o internalismo quanto à justificação se caracteriza essencialmente por uma Exigência de consciência $(\mathrm{EC})^{16}$, segundo a qual o que contribui para a justificação da crença em uma dada proposição para um dado sujeito deve ser evidência ou indicador da verdade dessa proposição, ou ser a satisfação de condição necessária para a justificação da crença, e "S está consciente (ou potencialmente consciente)" do item justificador ${ }^{17}$. Por conseguinte, (EC) em qualquer de suas modalidades, enquanto característica distintiva do internalismo, marca o ponto de divisão entre concepções internalistas e concepções externalistas de justificação, de modo que toda teoria que a aceita terá caráter internalista e toda teoria que a rejeita terá caráter externalista. Bergmann identifica corretamente na satisfação dessa exigência a motivação para o internalismo, como bem ilustrado no conhecido contraexemplo ao externalismo, proposto por BonJour, envolvendo a situação do clarividente Norman ${ }^{18}$. Mas, a argumentação de Bergmann procura inverter a direção da crítica, usando esse caso para tentar expor os flancos abertos das teorias internalistas que não conseguiriam escapar ao que ele denomina de Objeção da Perspectiva do Sujeito (OPS): "Se ao sustentar uma crença o sujeito não estiver consciente do que favorece essa crença, então ele não está consciente de como o seu estatuto pode ser diferente de um palpite ou convicção arbitrária"19.

16 "Awareness Requirement" ou "(AR)", no original. Cf. BERGMANN, Michael, Justification Without Awareness: A Defense of Epistemic Externalism, p. 9.

17 Ao considerar (EC), Bergmann avalia as possíveis combinações entre as modalidades de "consciência forte" e "consciência fraca", desdobrando-as em "atual" ou "potencial", e "doxástica" ou "não doxástica". Grosso modo colocado, para Bergmann a consciência do justificador só é forte caso o sujeito conceba, de modo atual ou potencial, o item relevante para a justificação, podendo ser do tipo doxástico ou não doxástico. A consciência do justificador será do tipo fraco quando o sujeito, apesar de estar consciente do justificador, não está igualmente consciente de seu papel contribuidor para a justificação da crença. Esse tipo de consciência pode ser de natureza conceitual ou não conceitual.

18 Norman, o clarividente concebido por BonJour, forma crenças invariavelmente verdadeiras a partir de seu dom. Contudo, a sua situação epistêmica é defeituosa uma vez que ele não tem qualquer evidência em favor de suas crenças, isto é, de sua perspectiva não há nada que indique a verdade dessas crenças. Epistemicamente falando, para Norman é apenas acidental que essas crenças sejam verdadeiras, de modo que ele não crê nelas justificadamente. Ao conceber o caso Norman, BonJour procura mostrar a força intuitiva da motivação internalista: apenas o fato de possuir razões em favor da (pelo menos provável) verdade de uma crença pode colocar o sujeito em posição favorável em termos de justificação.

19 "Subject's Perspective Objection" ou "(SPO)", no original. Cf. BERGMANN, Michael, Justification Without Awareness: A Defense of Epistemic Externalism, p. 12. 
Colocado sucintamente, conforme Bergmann, a exigência de posse consciente (atual ou potencial) das razões em favor da crença, exigência essa que constitui a motivação do internalismo, pode colocar o sujeito em situações epistemicamente tão desfavoráveis quanto a de Norman - a conjugação de (EC) com (OPS) colocaria o internalista em posição indefensável por levá-lo a um dilema funesto: se a consciência do justificador for fraca, o sujeito não o concebe em seu papel de contribuidor para a justificação da crença, (EC) não é satisfeita e o internalismo perde a sua razão de ser; se a consciência do justificador for forte, o sujeito concebe a relevância epistêmica do justificador, mas embarca em regresso infinito de justificações ${ }^{20}$.

A (OPS), conforme formulada por Bergmann, requer essencialmente que a justificação ocorra de modo a impedir que, do ponto de vista do sujeito, a verdade da crença seja meramente casual. Em sua concepção, apenas uma consciência forte, caracterizada pela ocorrência de um estado consciente de ordem superior que tem por objeto o item justificador e a sua relevância epistêmica, pode ser adequada para evitar a (OPS). Contra Bergmann, alguns internalistas alegam que a (OPS) pode ser evitada por uma consciência do justificador que permita não só a imediaticidade característica de uma relação não inferencial, mas também a disponibilidade cognitiva dos aspectos do conteúdo mental (talvez fracamente) consciente, que são relevantes para a verdade da proposição objeto de crença.

Recuperando resumidamente os aspectos centrais da objeção constituída pela associação de (EC) e da (OPS): (i) a exigência de consciência do justificador decorre da condição primordial do internalismo - de que o sujeito tenha dentro de seu alcance cognitivo os itens que contribuem para a justificação da crença enquanto indicadores da verdade da proposição objeto de crença, de modo que a verdade dessa proposição não é, da perspectiva do sujeito, meramente acidental; (ii) nessa exigência está a motivação central para a defesa de qualquer teoria internalista quanto à justificação epistêmica; (iii) o ponto crucial para a defesa do internalismo está em mostrar que conceber o item justificador em seu papel epistêmico não requer juízos, ou crenças de metanível, que resultam em regressos viciosos.

Identificar as condições para a satisfação da exigência de consciência do justificador é, com justiça, considerado como sendo um dos principais

$\overline{20}$ Explorei em maior detalhe o dilema de Bergmann tanto in: ETCHEVERRY, Kátia, O fundacionismo internalista de BonJour e seus críticos, in: Kínesis, 3:5 (2011), p. 298-308, quando abordei especificamente a aplicação dessa objeção à teoria de BonJour; quanto in: EADEM, Teorias fundacionistas e dilemas, in: DUTRA, L. H. de A. e LUZ, A. M. (orgs.), Temas de Filosofia do Conhecimento, Florianópolis: NEL/UFSC, 2011, p. 335-346, onde avaliei seu o impacto em versões de internalismo ditos de "consciência fraca". 
desafios colocados a teorias internalistas ${ }^{21}$, e como essas teorias lidam com essa questão é considerado um teste decisivo para mostrar que elas são explicações corretas de justificação. As próximas seções colocarão propostas de resposta ao problema de Bergmann desde duas concepções diferentes de internalismo, avaliando o seu sucesso em evitar as alternativas do dilema - regresso infinito e ceticismo ou perda da motivação internalista.

\section{Internalismo forte: Fundacionalismo Neoclássico}

O Fundacionalismo Neoclássico $(\mathrm{FN})^{22}$ é uma posição internalista forte, segundo a qual a uma crença $p$ só é justificada para um sujeito $S$ se $S$ tem algum tipo de acesso aos itens que justificam $p$ enquanto justificadores de $p$. Os fundacionalistas neoclássicos alegam que esse acesso é possível mediante a consciência imediata, ou contato cognitivo direto com itens (propriedades, estados de coisas ou fatos) que são relevantes para a verdade de crenças empíricas. É importante frisar que esses itens não são objetos, ou situações do mundo externo, mas apenas fatos internos à mente do sujeito podem ter os seus aspectos como objeto desse tipo de consciência ou de relação cognitiva. Nesses termos, a justificação de crenças básicas decorre da "confrontação direta com a verdade" 23 , proporcionada pela consciência direta, ou contato cognitivo direto, com aspectos do conteúdo fenomênico da experiência (fatos internos), o que permite a parada no regresso epistêmico ${ }^{24}$.

21 Para citar apenas alguns dos críticos do internalismo fundacionalista, cf. SELLARS, Wilfrid, op. cit., 1991; BERGMANN, Michael, BonJour's Dilemma, op. cit., p. 679-693; IDEM, Justification Without Awareness: A Defense of Epistemic Externalism, 2006; GOLDMAN, Alvin, Internalism Exposed, in: GOLDMAN, A., Pathways to Knowledge: Private and Public, New York: Oxford University Press, 2002, p. 3-23.

22 Adotei esta denominação a partir da sugestão de Timothy McGrew (1995), em referência à versão contemporânea de fundacionalismo internalista de inspiração cartesiana. Alguns defensores do (FN) são BONJOUR, L. A., Toward a Defense of Empirical Foundationalism, in: DEPAUL, M. (ed.), op. cit., p. 21-38; IDEM, A Version of Internalist Foundationalism, in: BONJOUR, L., and SOSA, E. (eds.), op. cit., p. 3-96; FUMERTON, Richard, Metaepistemology and Skepticism, 1995; IDEM, Classical Foundationalism, in: DEPAUL, M. (ed.), op. cit., p. 3-20; HASAN, Ali, Classical Foundationalism and Bergmann's Dilemma for Internalism, op. cit., p. 391-410; IDEM, Phenomenal Conservatism, Classical Foundationalism, and Internalist Justification, op. cit., p. 119-141; MCGREW, T., The Foundations of Knowledge, Lanham: Littlefield Adams Books, 1995.

23 Cf. FUMERTON, Richard, Classical Foundationalism, in: DEPAUL, M. (ed.), op. cit., p. 14.

${ }^{24}$ Embora não seja importante para a questão que abordamos no momento, é interessante observar que, devido à imediaticidade característica desse tipo de contato cognitivo com a realidade, a justificação que nele tem sua origem é infalível, pois não há nessa relação espaço para o erro, uma vez que a nossa mente não pode estar nesse tipo de relação com algo que não existe. Contudo, a propriedade de ser infalível se restringe à relação não inferencial que constitui a base epistêmica para as crenças não básicas empíricas, não atingindo a justificação que essas últimas obtêm a partir dessa base. 
Segundo BonJour ${ }^{25}$, para o fundacionalista internalista a base para a justificação não inferencial está na consciência direta (ou contato cognitivo direto) do justificador, o qual pode ser de natureza não proposicional. $O$ principal requisito para se constituir em justificador é que o sujeito esteja consciente tanto do item que contribui para a justificação da crença em questão quanto de sua relevância para a verdade dessa crença. Pela imediaticidade de sua natureza, a consciência direta (ou contato cognitivo direto) permite que o sujeito tenha acesso cognitivo direto a aspectos do conteúdo de estados mentais que estão, alegadamente,

[...] diretamente diante do 'olho' da mente [...] tais entidades ou características [do estado mental] são simplesmente parte da própria consciência, de modo que a sua consciência mais fundamental, aquela em virtude da qual elas existem em absoluto, não pode estar errada ${ }^{26}$.

Conforme Ali Hasan ${ }^{27}$, crenças perceptuais formadas por (um tipo especial de) conceitos demonstrativos podem ser justificadas por meio da "consciência direta ou contato cognitivo direto" de itens que constituem o próprio conteúdo que é objeto de crença, e que estão disponíveis cognitivamente de modo imediato enquanto justificadores, evitando assim a (OPS). Essa relação cognitiva direta é constituída pelo que Hasan denomina de "consciência atentiva"28, cujo foco está em aspectos do conteúdo experiencial, de modo que o sujeito ao formar a sua crença só pode fazê-lo com base no item epistemicamente relevante que é objeto de sua atenção consciente: "[...] para esse tipo de crença, entender genuinamente, ou compreender, o conteúdo da crença envolve essencialmente uma consciência de seu produtor da verdade" 29 . Por conseguinte, as únicas condições para a justificação não inferencial de uma dada crença seriam (i) a consciência direta de aspectos do conteúdo do estado experiencial que são relevantes para a verdade dessa crença; e (ii) a exigência de que o conteúdo da crença inclua um conceito demonstrativo se referindo diretamente a aspectos do conteúdo do estado experiencial. Desse modo, crenças do tipo estou experienciando isto ou me parece da seguinte maneira poderiam ser justificadas e básicas, pois a sua fundamentação seria fornecida por uma consciência direta do item justificador.

25 Cf. BONJOUR, L. A., In Search of Direct Realism, in: Philosophy and Phenomenological Research, 69:2 (2004), p. 349-367.

26 Id. ibid., p. 355.

27 A proposta de Hasan é fortemente influenciada pela teoria de precursores do fundacionalismo neoclássico como McGrew, BonJour e Fumerton.

28 No original, "attentive awareness"; cf. HASAN, Ali, Classical Foundationalism and Bergmann's Dilemma for Internalism, op. cit., p. 400.

29 Id. ibid., grifo meu. 
A partir desses elementos teóricos, Hasan alega que algumas características fenomênicas da experiência podem ser objeto de "consciência direta fraca", ao se colocarem imediatamente diante da mente, de modo que a relevância da experiência para a justificação da crença a ela relacionada se encontra dentro da perspectiva cognitiva do sujeito. Nesse sentido, uma sugestão interessante é feita por DePoe ${ }^{30}$ : um estado consciente pode ter conteúdo não proposicional e ainda assim ter um caráter conceitual, significativo cognitivamente, mesmo se não incluir conceitos que categorizam características refinadas, tais como formas geométricas e cores. Esse entendimento do modo como o conteúdo fenomênico da experiência consciente pode ser relevante epistemicamente representa uma contribuição importante no esforço de bloquear a estratégia de Bergmann de embretar o internalista, forçando-o a conceber a consciência do justificador de modo a torná-la trivialmente ineficiente do ponto de vista epistêmico, colocando-o assim, de modo inevitável, à mercê seja de regressos seja da (OPS).

\section{Internalismo fraco: Conservadorismo Fenomênico}

O internalismo defendido por M. Huemer ${ }^{31}$ é expresso pelo princípio do Conservadorismo Fenomênico (CF): "Se parece a $S$ que $p$ então, na ausência de derrotadores, $S$ tem, por conseguinte, pelo menos algum grau de justificação para crer que $p$ "32. Conforme (CF), crenças fundacionais podem ser prima facie justificadas por estados de aparências ${ }^{33}$, que seriam

30 Cf. DEPOE, John, Bergmann's Dilemma and Internalism's Escape, in: Acta Analytica, 27 (2012), p. 409-423.

31 Cf. HUEMER, Michael, Skepticism and the Veil of Perception, Lanham: Rowman e Littlefield Publishers, 2001; IDEM, Compassionate Phenomenal Conservatism, in: Philosophy and Phenomenological Research, 74:1 (2007), p. 30-55. Ampliações e a discussão sobre o Conservadorismo Fenomênico estão in: HUEMER, Michael, Phenomenal Conservatism Über Alles, in: TUCKER, C. (ed.), Seemings and Justification: New Essays on Dogmatism and Phenomenal Conservatism, New York: Oxford University Press, 2013, p. 328-349; MORETTI, Luca, Phenomenal Conservatism, in: Analysis, 75 (2015), p. 296-309; TUCKER, Chris, Seemings and Justification: An Introduction, in: TUCKER, C. (ed.). Seemings and Justification: New Essays on Dogmatism and Phenomenal Conservatism, New York: Oxford University Press, 2013, p. 1-29; STEUP, Matthias, Does Phenomenal Conservatism Solve Internalism's Dilemma?, in: TUCKER, Chris (ed.), Seemings and Justification: New Essays on Dogmatism and Phenomenal Conservatism, New York: Oxford University Press, 2013, p. 135-153.

32 Cf. HUEMER, Michael, Compassionate Phenomenal Conservatism, op. cit., p. 30.

${ }^{33}$ Existem diferentes tipos de aparências: intuitivas, perceptuais, mnemônicas e introspectivas, constituindo o tipo de estado mental que referimos quando dizemos "Me parece que p". In: HUEMER, Michael, Ethical Intuitionism, New York: Palgrave MacMillan, 2005, Capítulo 5, p. 102, o autor trata de epistemologia moral e atribui às intuições um papel epistêmico. Em sua concepção, uma intuição é uma aparência intelectual que não está baseada em nenhum raciocínio, mas se coloca no início de todo processo de raciocínio. Intuições podem, por conseguinte, fornecer uma base não inferencial e prima facie (falível) para determinadas crenças, porque intuições não dependem inferencialmente de outras crenças. 
estados não doxásticos, mas de natureza "proposicional e assertiva", o que lhes permitiria fornecer justificação não inferencial para crenças que sejam relacionadas a eles e tenham o mesmo conteúdo proposicional. Apesar de seu conteúdo ser de natureza proposicional, para Huemer e a maioria dos demais defensores de (CF) aparências diferem de crenças e de disposições para crer: não são crenças, porque pode parecer ao sujeito que $p$ sem que ele creia que $p$, e não são disposições para crer, porque pode parecer ao sujeito que $p$ e ele ter uma contraevidência que o impede de crer que $p^{34}$. Portanto, em situações normais, se parece a você perceptualmente (introspectivamente, intuitivamente, mnemonicamente) que $p$, então crer que $p$ é razoável para você, porque a sua crença de que $p$ estaria baseada em aparências de que $p$ e, portanto, justificada prima facie. (CF) se qualificaria como teoria internalista da justificação, conforme alega Huemer, devido ao fato de aparências serem estados internos à mente do sujeito dos quais ele, plausivelmente, pode se tornar consciente, inclusive de sua relevância para o estatuto justificacional de suas crenças.

Embora não haja nenhuma exigência de acesso às aparências em seu papel justificacional, Huemer alega que (CF) satisfaz a (EC) e escapa de objeções como a (OPS), configurando assim a melhor explicação internalista de justificação não inferencial ${ }^{35}$. Vejamos como. De acordo com a explicação de justificação não inferencial oferecida em (CF), toda crença que formamos em situações de normalidade (isto é, excluindose casos como os de autoengano, fé ou problemas de saúde) está baseada em como as coisas nos parecem ser, porque "o modo como as coisas nos parecem é normalmente o único fator relevante causalmente (imediato) na formação da crença" ${ }^{36}$. Contudo, não é ponto pacífico que as aparências sejam a "única" base justificacional de crenças, por serem, alegadamente, a sua causa mais imediata. Consideremos a hipótese de

${ }^{34}$ Cf. HUEMER, Michael, Compassionate Phenomenal Conservatism, op. cit., p. 30-31.

35 Cf. HUEMER, Michael, Phenomenal Conservatism and the Internalist Intuition, in: American Philosophical Quarterly, 43:2 (2006), p. 147-158.

36 Cf. HUEMER, Michael, Compassionate Phenomenal Conservatism, op. cit., p. 39. Nessa alegação estaria parte da fundamentação em favor de (CF), segundo a qual nenhuma teoria poderia rejeitar $(\mathrm{CF})$ senão baseando a sua crença na negação de (CF) no que lhe parece ser verdadeiro; portanto, negar $(\mathrm{CF})$ leva à autorrefutação. $\mathrm{O}$ argumento da autorrefutação levantado por Huemer tem encontrado importante resistência entre os críticos de (CF); contudo, como esse debate é apenas tangencial ao foco desse artigo, qual seja, o sucesso de (CF) como teoria internalista da justificação, limito-me a indicar algumas referências: DEPOE, John, Defeating the Self-Defeat Argument for Pheomenal Conservativism, in: Philosophical Studies, 152 (2011), p. 347-359; HUEMER, Michael, Compassionate Phenomenal Conservatism, op. cit., p. 30-55; IDEM, Phenomenal Conservatism and Self-Defeat: A Reply to DePoe, in: Philosophical Studies, 156 (2011), p. 1-13; HUEMER, Michael, Phenomenal Conservatism Über Alles, in: TUCKER, C. (ed.), op. cit., p. 328-349. 
que a base relevante para a crença de que $p$ seja o fato de que $p$. Nesse caso, uma pessoa só creria que $p$ quando $p$ fosse o caso. Porém, casos de ilusão e alucinação, nos quais a pessoa crê que $p$ porque parece a ela que $p$ (parecer-lhe que $p$ é a causa de sua crença), e não devido ao fato de que $p$ (simplesmente porque tal fato não ocorre), mostram que pode acontecer de modo diverso. Não parece incoerente sugerir que a proposta de Huemer é compatível com o entendimento de que aparências não seriam causadas diretamente por fatos externos ao sujeito, mas pelo conteúdo fenomênico da experiência, e que aparências, por sua vez, seriam a causa de nossas inclinações para crer, pois "[...] em condições normais, o modo como as aparências determinam crenças é inclinandonos a crer no que nos parece ser [verdade], em oposição a, por exemplo, inclinar-nos a crer em coisas que nos parecem falsas" 37 .

A plausibilidade da alegação de que aparências são a causa de "inclinações para crer" não impede a bem acertada crítica a (CF) formulada por Ali Hasan ${ }^{38}$ : podemos negar (CF) negando que aparências sejam os únicos itens relevantes para a justificação da crença, ou mesmo os mais relevantes, segundo critérios internalistas, mesmo se aceitarmos que apenas as causas imediatas de uma crença podem ser a sua base ${ }^{39}$. Uma crença pode ter diversas fontes de justificação que, em conjunto, fornecem boas razões para a crença, de modo que, mesmo se aparências forem a causa mais imediata de uma crença, elas podem não ser a sua única base, porque, plausivelmente, uma crença pode não ter como base apenas a sua causa mental imediata. Finalmente, mas não menos importante, Hasan alega que existe "um contato cognitivo direto por detrás da aparência", constituindo o que seria "uma causa distal" em termos de constituição da base epistêmica de crenças, e esse contato cognitivo direto seria o responsável pela satisfação da condição internalista de consciência do justificador.

Um defensor do (FN) poderia aceitar o seguinte esquema: primeiramente, o sujeito tem uma experiência sensorial consciente, na sequência a relação de contato cognitivo direto com aspectos do conteúdo fenomênico dessa experiência dá condições para a ocorrência de um estado de aparência, o qual por sua vez ocasiona uma disposição para crer, que resulta finalmente em um estado de crença. Consequentemente, esses teóricos do contato cognitivo direto poderiam aceitar (a) que as aparências podem conduzir à crença de que $p$ mesmo quando não há contato cognitivo direto com o fato de que $p$ (aparências causam as

37 Cf. HUEMER, Michael, Compassionate Phenomenal Conservatism, op. cit., p. 39.

${ }^{38}$ Cf. HASAN, Ali, Phenomenal Conservatism, Classical Foundationalism, and Internalist Justification, op. cit., p. 119-141.

39 Id. ibid., p. 124. 
disposições para crer), mas nesse caso as crenças não seriam justificadas; e (b) que o contato cognitivo direto com o fato de que $p$ pode não conduzir à crença de que $p$ quando não há uma aparência de que $p$ (aparências teriam o caráter psicológico de acompanhar relações de contato cognitivo direto); e ainda assim podem negar que (c) aceitar as alegações (a) e (b) implique aceitar que a aparência de que $p$ é a única base para a crença de que $p$. Em favor dessa conclusão, temos situações nas quais a relação de contato cognitivo direto parece dispensar a ocorrência de estados de aparência, como é o caso de crenças formadas com base na introspecção, tais como a crença de que sinto dor, para as quais não há necessidade de um estado intermediário de parecer sentir dor. É plausível considerar que a crença seja causada pela própria dor, não sendo preciso a ocorrência de nenhuma aparência, caso em que a causa mais imediata da crença introspectiva não seria uma aparência.

Huemer afirma que (CF) é uma teoria internalista, sendo assim ele deve enfrentar a exigência internalista de consciência dos contribuidores da justificação. O ponto nevrálgico, bem identificado por Hasan, está no efeito que aparências podem ter na perspectiva cognitiva do sujeito. Afinal, é preciso esclarecer o que está na perspectiva do sujeito, quando parece a ele que $p$. Se aparências são, como alega Huemer, estados intencionais não doxásticos, não está claro como aparências podem ser epistemicamente relevantes na perspectiva do sujeito. Superada essa obscuridade, restaria ainda mostrar que as aparências têm relevância epistêmica maior ou anterior à relevância epistêmica da relação de contato cognitivo direto ou de consciência direta. Outra alternativa talvez seja conceber as aparências em termos de consciência direta ou de contato cognitivo direto, isto é, quando parece a $S$ que $p, S$ está em contato cognitivo direto com, ou tem consciência direta de que $p$ é o caso. Mas, a fim de satisfazer as condições internalistas (condições essas que só são satisfeitas quando as razões ou as evidências que conectam, em algum grau, a crença à sua verdade estão dentro da perspectiva do sujeito), é preciso ainda mostrar como, nessa situação, $S$ dispõe de alguma indicação de que $p$ é o caso devido às aparências, de modo exclusivo ou pelo menos principalmente, e não à relação de contato cognitivo direto. Como Fumerton coloca, para que seja plausível uma teoria da justificação não inferencial tem de "trazer o produtor da verdade da crença para dentro da história sobre o que constitui a justificação não inferencial" ${ }^{40}$. Se o produtor da verdade estiver imediatamente presente

40 Cf. FUMERTON, Richard, Epistemic Conservatism: Theft or Honest Toil?, in: GENDLER, Tamar S., and HAWTHORNE, J. (eds.), Oxford Studies in Epistemology - Volume 2, Oxford: Oxford University Press, 2007, p. 63-86. 
à consciência, a crença relevante está justificada, porque o próprio produtor da verdade é um dos constituintes do estado consciente que acompanha a crença que o tem por objeto, e a relação de correspondência entre eles é "transparente" 41 . Para que estados de aparências possam fazer diferença, do ponto de vista epistêmico e na perspectiva do sujeito, é preciso especificar em que condições essas aparências podem ser por si mesmas, para o sujeito que crê, indicações da verdade da proposição que é objeto de sua crença.

John $\mathrm{DePoe}^{42}$ argumenta na mesma direção de Hasan: aparências não são a única base plausível para a formação de crenças, a relação de contato cognitivo direto pode ser uma base apropriada e independente de aparências, e pode também colocar o sujeito em situação cognitiva favorável para a satisfação das condições internalistas para a justificação. DePoe $^{43}$ sugere como contraexemplo a $(\mathrm{CF})$ o seguinte experimento mental: imaginemos pessoas muito semelhantes a nós mesmos, que têm contato cognitivo direto com algum fato interno, mas, por alguma mutação que as torna diferentes de nós, elas não têm nenhuma aparência que acompanhe a relação de contato cognitivo direto, ou as aparências que elas porventura tenham não têm nenhuma correlação nomológica com essa relação. Conforme as condições de (CF), essas pessoas não estariam justificadas em crer que têm dor devido à ausência de estados de aparências. Contudo, estando presente a relação de contato cognitivo direto, essas pessoas estão em condições de crer justificadamente que sinto dor.

Nessa perspectiva, se é fato que, quando uma pessoa está justificada em crer que $p$ com base em contato cognitivo direto, essa pessoa também tem (talvez necessariamente) um estado de aparência de que $p$, ainda assim a observação empírica de que aparências sempre acompanham toda crença humana seria apenas de relevância psicológica, e não epistemológica. É cabível considerar que a justificação dessas crenças provém do fundamento fornecido pela relação de contato cognitivo direto com o fato interno, produtor da verdade da crença. Por conseguinte, a relação de contato cognitivo direto parece colocar o sujeito na melhor posição epistêmica possível, resultando em fundamento especialmente forte para a sua crença e satisfazendo os critérios internalistas, sem gerar regressos viciosos, constituindo-se, afinal, na melhor explicação de justificação não inferencial internalista.

41 Id. ibid., p. 78-79.

42 DEPOE, John, Defeating the Self-Defeat Argument for Phenomenal Conservativism, op. cit., p. 347-359; HUEMER, Michael, Phenomenal Conservatism and Self-Defeat: A Reply to DePoe, op. cit., p. 1-13, responde às críticas de DePoe.

43 DEPOE, John, Defeating the Self-Defeat Argument for Phenomenal Conservativism, op. cit., p. 353. 
Para discordar da conclusão do parágrafo anterior, o defensor de (CF) deve esclarecer como aparências podem contribuir para a justificação de crenças de sujeitos como Norman o clarividente, colocando dentro da perspectiva cognitiva do sujeito as indicações da verdade de sua crença. É importante salientar que aparências só podem ser itens relevantes epistemicamente se puderem se apresentar, desde o ponto de vista do sujeito, como conexões apropriadas entre a crença e o fato que a torna verdadeira, isto é, enquanto conexão evidencial entre a crença e os seus justificadores que está cognitivamente disponível ao sujeito. Se a aquisição da qualificação epistêmica da crença finalmente for efetivada pelo fato de $S$ estar em contato direto (ou diretamente consciente) com o item justificador, então a base epistêmica relevante está na relação de contato cognitivo cognitivo direto (ou a consciência direta). Sendo assim, é plausível considerar que aparências nada mais são do que estados psicológicos que tipicamente acompanham crenças baseadas em contato cognitivo direto.

Alternativamente, se a alegação dos defensores de (CF) for de que as aparências fornecem justificação para crenças porque são causadas por fatos externos (tais como objetos e eventos do mundo físico), então a resposta dos críticos pode ser direta: uma relação causal não pode ser epistemicamente relevante, dado que ela não é algo de que o sujeito possa estar consciente. Isso nos leva a outro efeito indesejado da proposta de Huemer, identificado por DePoe:

\begin{abstract}
Assim, um segundo problema com o argumento de Huemer em favor de $\mathrm{CF}$ é o de que ele imporia ao internalista uma exigência de fundamentação que permitiria casos paradigmáticos de justificação externalista levemente modificados (como o do clarividente de BonJour e o Sr. Truetemp de Lehrer) terem algum grau de justificação interna [...]; se aparências fossem bons fundamentos para justificar crenças, os casos paradigmáticos de justificação externalista levemente modificados se tornariam bons casos de justificação interna. Ademais, se a aparência de que $p$ e o fato de que $p$ não têm nenhuma conexão evidencial desde a perspectiva do sujeito, então internalistas devem abandonar a concepção de Huemer ${ }^{44}$.
\end{abstract}

\title{
5 Considerações finais
}

Aleguei anteriormente que a explicação de justificação oferecida por $(\mathrm{CF})$ é insatisfatória do ponto de vista internalista, porque não está claro como estados de aparências podem fazer alguma diferença na

44 Id. ibid., p. 358. 
perspectiva do sujeito quanto à verdade de suas crenças. A alegação de que as aparências seriam as causas mais imediatas de crenças não é suficiente para conceder às aparências relevância epistêmica, uma vez que (i) elas não são as únicas causas imediatas para crenças, afinal a relação de contato cognitivo direto (ou consciência direta) dos justificadores também compõe esta base; além disso, (ii) ser uma causa imediata não significa ser epistemicamente relevante. Para a adequada compreensão desses comentários finais, será útil recuperar alguns aspectos teóricos.

A motivação de $(\mathrm{CF})$ está na intuição de que somos racionais ao crer com base no modo como as coisas nos parecem ser, a menos que tenhamos razões em contrário. Portanto, aparências podem fornecer base epistêmica (conforme (CF), a única base), prima facie ou derrotável, para nossas crenças sobre situações e objetos do mundo exterior. A justificação não inferencial própria das crenças básicas seria dada por relação epistêmica direta com as aparências, e seria internalista porque aparências são estados internos à mente do sujeito, os quais, conforme o entendimento dominante entre os defensores de (CF), constituem um tipo de experiência com conteúdo proposicional.

Como um conteúdo pode ser proposicional sem ser uma crença? $E$ É interessante referir que BonJour ${ }^{45}$ também atribui à consciência constitutiva, que é inerente a um estado de experiência consciente, a natureza de ser "assertiva". Apesar de não ser claro como o conteúdo da experiência pode ser assertivo e, ao mesmo tempo, não proposicional, parece cabível depreender dos termos de BonJour que essa consciência pode ser a base da justificação da crença experiencial precisamente por desempenhar, pelo menos aproximadamente, o mesmo papel epistêmico que Huemer atribui às aparências: a própria fenomenologia do conteúdo do estado mental - seja de consciência constitutiva, seja de aparência - forneceria ao sujeito, desde a sua perspectiva, o sentimento de que determinada proposição é verdadeira. Minha sugestão, ainda que provisória, é a de que a força assertiva tanto da consciência constitutiva quanto da aparência seria devida à formação de conceitos fenomênicos via relação de contato cognitivo direto ${ }^{46}$. Ou seja, a consciência de conteúdo constitutiva ou a aparência podem tornar disponível cognitivamente ao sujeito a base justificacional de sua crença graças à conceitualização de aspectos do conteúdo fenomênico da experiência sensória, mediante relação de contato cognitivo direto (ou de consciência direta). Por

45 Cf. BONJOUR, L. A., A Version of Internalist Foundationalism, in: BONJOUR, L., and SOSA, E. (eds.), op. cit., p. 3-96.

46 Cf. ETCHEVERRY, Kátia, Justificação fundacional: a explicação neoclássica, Porto Alegre: PPG em Filosofia da PUCRS (Tese de Doutorado), 2013. 
conseguinte, a fonte da justificação estaria nessa relação de contato cognitivo direto com aspectos do conteúdo fenomênico da experiência.

Há, contudo, um ponto distintivo importante entre as concepções de BonJour e de Huemer: enquanto o primeiro assume o representacionalismo, o último defende o realismo direto. Nesse caso, a vantagem para Huemer seria a de uma explicação simplificada de como podemos ter crenças justificadas sobre o mundo exterior, dispensando a complicação, enfrentada por teorias representacionalistas, envolvendo a explicação de como podemos inferir crenças sobre estados de coisas que são externos a nós, a partir da base epistêmica constituída pelo conteúdo de nossos estados mentais. Em contrapartida, o realista direto também tem o seu ônus, pois deve explicar como podemos distinguir aparências que são diretamente causadas pelos objetos físicos, de outras aparências causadas por estados mentais de outra ordem, tais como imaginação, desejo, emoções e mesmo crenças. Essa objeção tem sido colocada por alguns críticos de (CF) sob o rótulo de "penetração cognitiva", traduzida pela influência, prejudicial ou benéfica, que a participação de outros estados cognitivos podem ter na causação de determinada aparência ${ }^{47}$.

Ao assumir uma posição realista direta, (CF) deve oferecer uma resposta específica a argumentos como o da alucinação, pois, ao contrário do que Huemer ${ }^{48}$ supõe, não pode ser estabelecida uma analogia entre situações de erro perceptual e casos de má penetração cognitiva. A explicação dada pelos representacionalistas ao argumento da alucinação está disponível apenas para aqueles que assumem o realismo indireto. Para esses, em casos de alucinação ou ilusão, aqueles que têm experiências perceptuais verídicas e aqueles que são vítimas de erro perceptual estão igualmente justificados, porque (i) ambos têm a mesma base justificacional, isto é, o conteúdo de seus estados de experiência conscientes; e (ii) ambos os referidos estados têm o mesmo conteúdo fenomênico. Consequentemente, a situação evidencial de ambos os sujeitos lhes permite ter crenças igualmente racionais, ainda que com diferentes valores de verdade. $O$ fato de a causa da experiência verídica ser um objeto real, ao contrário da causa da alucinação, não é relevante para a racionalidade da crença, pois não está disponível cognitivamente para o sujeito. Aquele que percebe veridicamente, crê justificadamente

${ }^{47}$ Cf. HUEMER, Michael, Phenomenal Conservatism Über Alles, in: TUCKER, C. (ed.), op. cit., p. 328-349; LYONS, Jack, Circularity, Reliability, and the Cognitive Penetrability of Perception, in: Philosophical Issues, 21 (2011), p. 289-311; TUCKER, Chris, Seemings and Justification: An Introduction, in: TUCKER, C. (ed.), op. cit., p. 1-29.

48 Cf. HUEMER, Michael, Phenomenal Conservatism, in: Internet Encyclopedia of Philosophy, 2013, disponível in: < http://www.iep.utm.edu/phen-con/>; IDEM, Phenomenal Conservatism Über Alles, in: TUCKER, C. (ed.), op. cit., p. 328-349. 
uma proposição verdadeira sobre o mundo; aquele que é vítima de uma alucinação, crê justificadamente em uma proposição falsa sobre o mundo. Se ambos formarem crenças sobre o conteúdo de seu estado mental do tipo creio que me parece que tal e tal, essas crenças serão ambas, não apenas justificadas, mas também verdadeiras.

Portanto, no caso de um sujeito ter uma aparência causada por má penetração cognitiva (por exemplo, causada por desejos ou por imaginação), essa aparência não poderia conferir nem mesmo justificação derrotável, pois a sua origem a ilegitimaria enquanto justificador. Se o defensor de (CF) mudar a sua concepção e retirar do fator causal proporcionado pelo realismo direto a importância epistêmica que ora lhe é atribuída, então a dimensão representacional da aparência terá essa importância, não se distinguindo assim de uma posição representacionalista.

De todo modo, admitindo-se que se trate de uma teoria internalista da justificação, (CF) conseguiria escapar ao dilema de Bergmann? Como vimos anteriormente, condições internalistas para a justificação, aquelas que capturam a intuição essencial do internalismo e o caracterizam de modo a distingui-lo de qualquer explicação externalista, exigem que o sujeito tenha posse do que justifica a sua crença, de maneira a evitar que de sua perspectiva a verdade da crença seja acidental (a exemplo do caso Norman). Conforme a objeção formulada por Bergmann, a faca internalista corta pelos dois lados, pois ao exigir a posse consciente do justificador enquanto justificador (isto é, em sua relevância epistêmica), o internalista se coloca diante de uma situação sem saída: ou satisfaz a condição internalista de acesso cognitivo ao justificador e se coloca diante de um regresso infinito de justificações, ou não satisfaz essa condição de acesso, caso em que não seria uma posição diferente do externalismo.

O ponto arquimediano da contra-argumentação internalista tem de incluir a recusa em conceber que esse acesso requeira, como quer Bergmann, uma consciência que forçosamente exige a ocorrência de um estado de nível superior, tendo como objeto tanto o justificador quanto a sua contribuição para a justificação da crença. Tudo o que o internalista precisa aceitar é a exigência de que a consciência do justificador permita ao sujeito, de modo imediato, compreender a relevância do justificador para a qualificação epistêmica da crença em questão. Para isso, bastaria que essa consciência fosse caracterizada por um conteúdo constituído por conceitos fenomênicos diretos, adequados para que o sujeito tenha acesso cognitivo ao justificador e ao seu papel epistêmico, proporcionando assim a base epistêmica para a crença relevante, com certo grau de segurança epistêmica ao afastar a eventualidade de a verdade da crença ser, para o sujeito, um mero acaso. Esse parece ser o caso de uma crença justificada 
não inferencialmente com base na relação de contato cognitivo direto não parece cabível que o sujeito tenha contato cognitivo direto com a correspondência entre o seu pensamento e o fato produtor da verdade do pensamento, isto é, a sua experiência sensória, e não conceba o papel justificador dessa experiência.

O externalismo é acusado de não satisfazer a objeção da perspectiva do sujeito (OPS). E quanto a (CF)? Se a aparência de que o presidente está em Nova Iorque for adicionada à situação do clarividente Norman, essa situação seria melhor do ponto de vista epistêmico? Se não for esclarecido como aparências são indicadores da verdade de uma proposição, o seu caráter será meramente psicológico e, portanto, irrelevante epistemicamente. A satisfação dos critérios internalistas em geral requer, grosso modo e com algumas variantes, que as relações epistêmicas ou evidenciais entre crenças e seus justificadores sejam, de alguma forma, acessíveis ao sujeito. Norman tem essa perspectiva? O que lhe parece pode fornecer suporte evidencial para a sua crença? Considero que não. Seria cabível aceitar que aparências frequentemente acompanham relações de contato cognitivo direto, talvez até sejam causadas por relações dessa natureza? Referi anteriormente que experiências de dor mostrariam que podemos ter crenças que não são causadas por aparências, e que, mesmo em casos nos quais as aparências seriam a causa de inclinações para crer, a justificação da crença se deveria a uma relação de contato cognitivo direto com o conteúdo fenomênico, que é prévia à aparência e que plausivelmente lhe dá causa. Nesse caso, claramente a base justificacional estaria na relação de contato cognitivo direto, e não no estado de aparência.

Para que a posição defendida por Huemer possa ser considerada internalista e que a aparência de que $p$ possa dar suporte evidencial à crença de que $p$, é preciso que a relação entre a aparência de que $p$ e o fato de que $p$ esteja disponível cognitivamente ao sujeito. Se essa relação for, afinal, como parece ser, precisamente a relação de contato cognitivo direto invocada pelas teorias defensoras de (FN), então (CF) não se distingue delas.

\section{Referências}

ALSTON, William. Epistemic Desiderata. In: Philosophy and Phenomenological Research, $53: 3$ (1993), p. 527-551.

BERGMANN, Michael. BonJour's Dilemma. In: Philosophical Studies, 131 (2006), p. 679-693.

. Justification Without Awareness: A Defense of Epistemic Externalism. Oxford:

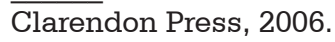


. Phenomenal Conservatism and the Dilemma for Internalism. In: TUCKER, C. (ed.). Seemings and Justification: New Essays on Dogmatism and Phenomenal Conservatism. New York: Oxford University Press, 2013. p. 154-176.

BONJOUR, L. A Version of Internalist Foundationalism. In: BONJOUR, L.; SOSA, E. (eds.). Epistemic Justification: Internalism vs. Externalism, Foundations vs. Virtues. Malden: Blackwell Publishers, 2003, p. 3-96.

. In Search of Direct Realism. In: Philosophy and Phenomenological Research, 69:2 (2004), p. 349-367.

. Replies. In: Philosophical Studies, 131 (2006), p. 743-759.

. Toward a Defense of Empirical Foundationalism. In: DEPAUL, M. (ed.). Resurrecting Old-Fashioned Foundationalism. Oxford: Rowman \& Littlefield Publishers, 2001. p. 21-38.

CRISP, Thomas. A Dilemma for Internalism? In: Synthese, 174 (2010), p. 355-366.

DEPOE, John. Bergmann's Dilemma and Internalism's Escape. In: Acta Analytica, 27 (2012), p. 409-423.

Defeating the Self-Defeat Argument for Phenomenal Conservativism. In: Philosophical Studies, 152 (2011), p. 347-359.

ETCHEVERRY, Kátia. Justificação fundacional: a explicação neoclássica. 2013. 139p. Tese (Doutorado) - Programa de Pós-Graduação em Filosofia da Pontifícia Universidade Católica do Rio Grande do Sul, Porto Alegre.

O fundacionismo internalista de BonJour e seus críticos. In: Kínesis, 3:5 $\overline{(2011)}$, p. 298-308.

. Teorias fundacionistas e dilemas. In: DUTRA, L. H. de A.; LUZ, A. M. (Orgs.). $\overline{\text { Temas }}$ de Filosofia do Conhecimento. Florianópolis: NEL/UFSC, 2011. p. 335-346. (Coleção Rumos da Epistemologia, 11).

FELDMAN, R.; CONEE, E. Internalism Defended. In: SOSA, E.; KIM, J.; FANTL, J.; MCGRATH, M. (eds.). Epistemology: An Anthology. Malden: Blackwell Publishing, 2009. p. 407-421. (Reimpressão do texto originalmente publicado in: The American Philosophical Quarterly, 38 (2001), p. 1-18.)

FUMERTON, Richard. Classical Foundationalism. In: DEPAUL, M. (ed.). Resurrecting Old-Fashioned Foundationalism. Oxford: Rowman \& Littlefield Publishers, 2001. p. 3-20.

Epistemic Conservatism: Theft or Honest Toil?. In: GENDLER, Tamar S.; HAWTHORNE, J. (eds.). Oxford Studies in Epistemology. Oxford: Oxford University Press, 2007. Vol. 2, p. 63-86.

1995.

. Metaepistemology and Skepticism. Lanham: Rowman \& Littlefield Publishers,

GOLDMAN, Alvin. Epistemology and Cognition. Cambridge: Harvard University Press, 1986.

. Internalism Exposed. In: GOLDMAN, A. Pathways to Knowledge: Private and Public. New York: Oxford University Press, 2002,. p. 3-23. (Reimpressão do texto originalmente publicado in: The Journal of Philosophy, 96 (1999), p. 271-293.)

. What is Justified Belief? In: PAPPAS, G. (ed.). Justification and Knowledge. Dordrecht: D. Reidel, 1979. p. 1-23. 
HASAN, Ali. Classical Foundationalism and Bergmann's Dilemma for Internalism. In: Journal of Philosophical Research, 36 (2011), p. 391-410.

. Phenomenal Conservatism, Classical Foundationalism, and Internalist Justification. In: Philosophical Studies, 162:2 (2013), p. 119-141.

HUEMER, Michael. Compassionate Phenomenal Conservatism. In: Philosophy and Phenomenological Research, 74:1 (2007), p. 30-55.

. Ethical Intuitionism. New York: Palgrave MacMillan, 2005.

. Phenomenal Conservatism. In: Internet Encyclopedia of Philosophy, 2013. Avaliable from: <http://www.iep.utm.edu/phen-con/>.

. Phenomenal Conservatism and Self-Defeat: A Reply to DePoe. In: Philosophical Studies, 152 (2011), p. 347-359.

. Phenomenal Conservatism and the Internalist Intuition. In: American Philosophical Quarterly, 43:2 (2006), p. 147-158.

. Phenomenal Conservatism Über Alles. In: TUCKER, C. (ed.). Seemings and Justification: New Essays on Dogmatism and Phenomenal Conservatism. New York: Oxford University Press, 2013. p. 328-349.

\section{1.}

. Skepticism and the Veil of Perception. Lanham: Rowman e Littlefield Publishers,

LYONS, Jack. Circularity, Reliability, and the Cognitive Penetrability of Perception. In: Philosophical Issues, 21 (2011), p. 289-311.

MORETTI, Luca. Phenomenal Conservatism. In: Analysis, 75 (2015), p. 296-309.

MCGREW, T. The Foundations of Knowledge. Lanham: Littlefield Adams Books, 1995.

NOZICK, Robert. Philosophical Explanations. Cambridge, MA: Belknap Press, 1981.

PLANTINGA, Alvin. Warrant: The Current Debate. Oxford: Oxford University Press, 1993.

ROGERS, Jason; MATHESON, Jonathan. Bergmann's Dilemma: Exit Strategies for Internalists. In: Philosophical Studies, 152 (2011), p. 55-80.

SELLARS, Wilfrid. Science, Perception and Reality. Atascadero: Ridgeview, 1991.

STEUP, Matthias. Does Phenomenal Conservatism Solve Internalism's Dilemma?. In: TUCKER, Chris (ed.). Seemings and Justification: New Essays on Dogmatism and Phenomenal Conservatism. New York: Oxford University Press, 2013. p. 135-153.

TUCKER, Chris. Seemings and Justification: An Introduction. In: TUCKER, C. (ed.). Seemings and Justification: New Essays on Dogmatism and Phenomenal Conservatism. New York: Oxford University Press, 2013. p. 1-29. 